University of Michigan

The breakdown of human literacy, of which various symptoms are evident, the disquiet about whether poetry is any longer important or the conviction that it is not, must not be shrugged off. Rather should it sharpen our sense of the significant, of the works we choose to includethat means to interpret and communicate-in our new complications. It can be read as urgent warning against getting permanently lost in the Pedagogical Provinces, while the province itself flounders. (Murray, 1975, p. 8)

What does it mean to be literate in a world which is increasingly dominated by a technological image of the lifeworld? What does $h u-$ man literacy mean in a milieu of technical competency, of functional rationality, of management science, of behavioral engineering? Clearly the pedagogical provinces are floundering as communication has increasingly assumed the form of technical communication with measurable input/output variables, with demonstrable objectives, with predictable outcomes. In such a province the meaning of the pedagogical relationship, the dialogical encounter, that creates the framework for a liberatory critical process, is condemned as ideological and indeed anti-educational.

Maxine Greene has talked of how literacy has become a commodity -where our educational reality is mystified and structured so as to create an illusion that technical training, skill mastery, and a demonstrable devotion to efficiency constitute a natural order-the "given" of educational life. She argues, as does Murray, for the return to the aesthetic-as paradigmatic for all domains for it is art and poetry that empower us to move within and beyond-that enable us "to look" (Greene, 1980).

It seems that if we understand literacy as a complex interweaving of pedagogy and praxis, as a fundamentally human action of a wideawake adult, where "to speak a true word is to transform the world" (Freire, 1970, p. 75), our very practice as educators and researchers, as professionals and social scientists is thrown into sharp relief against the backdrop of our culture of silence-of the academic "massification" and intellectual legitimation of the notion of scientific neutrality in the educational process. Our ways of thinking and our ways of explaining are invaded by a technical rationality that creates what Freire has termed a "focalistic vision"-in which subjective meaning and action, and human events are isolated from the socio-cultural milieu in which they are embedded and are analyzed in alienation from the lifeworld context. The political charac- 
ter of the educational process needs to be unveiled. We need to understand the social organization of knowledge as embedded in specific material conditions which underlie the prevailing hierarchies of power and dominant cultural ideologies of our time. Once the myth of neutrality of the educational process is shattered, the possibility for critically reflecting on what it means "to know," "to teach," and "to do research" emerges as a call to action. Freire tells us:

There is no true word that is not at the same time a praxis-to exist humanly is to name the world, to change it. Once named, the world in its turn reopens to the namers as a problem and requires of them a new naming. (Freire, 1970, p. 76).

\section{The New Naming}

At this point I would like to consider the meaning of a critical pedagogy in the context of graduate research training in Education and Social Science.

As a former doctoral student and current faculty member in the School of Education, I, like many others, have encountered the typical problems that beset graduate students when they are expected to create research "designs" as they are so termed. This invariably necessitates the use of quantitative methodology, ranging from the "soft" instruments such as interview questionnaires to the "hard" technology of the computer.

The ensuing process is such that frequently the researcher is not directed to the posing of fundamental questions, to "problematising" reality (as Freire would say), to the creation of impressionistic narratives gleaned from the lifeworlds of one's informants, nor to the generation of grounded interpretations. Rather there is a narrow focus on creating problems that can be answered, on constructing sophisticated measurement techniques to test hypotheses that, in their very formulation, bear the promise of yielding a product. Hence research, like literacy, has become a commodity-and problem-creating-and-solving a trade in which dissertation bartering and project selling flourish in a lucrative market.

Research courses accordingly teach students "how to do it," fostering through this "focalistic" vision a trained incapacity for critical and penetrating social analysis. The goals of such training are functionally pragmatic-geared to the production of results, written in the jargon of verification, and designed not to transform, but to maintain the social reality of the researcher's privileged world.

Freire $(1970,1973)$ in analyzing the "mode of massification" prevalent in highly industrialized technological societies writes of the subtle domestication of one's critical faculties successfully perpetuated by a "banking" approach to education. The research acculturation process that the graduate student researcher is forced to under- 
go as part of the "rites of passage" into the social science community leads to a further anaesthetizing of consciousness-of a "forgetfulness of being." It is only when we re-situate the research process in the full social and historical horizons of daily life, when we recognize and reclaim our own lived subjectivity as an essential component of the ongoing life context, that we find ourselves participating in this experience together with our informants. It is at that point that the research process as "dialogical encounter" can be "carried on by persons who are situated in the concreteness of the world, by persons equipped for interrogation, for problematization, and for hermeneutic interpretation of the culture - of the present and the past" (Greene, 1978, p. 108).

Hence the "new naming" requires a new vocabulary, a new grammar of social relationships, another syntax for intersubjective meaning. Without the linguistic medium to recreate these alternative social forms, the hermeneutic counter-text emerges as mere pale shadow of the positivist image.

How does one create a new grammar, another way of being, pedagogically? In this regard I would like to describe my own experience as both "teacher" and "learner" in a research course sequence in the human sciences.

In 1980, after much political ado and ideological opposition, the first human science course sequence worked its way through various bureaucratic channels and attained official legitimation. The sequence was unofficially approved as a dubious alternative research sequence for graduate students who had received their "basic scientific" training in a statistics course. The course is now in its third year of existence, alternately taught by my colleague, Biff Barritt, and myself, and attracts students from a wide variety of disciplines ranging from education, architecture, and social work to English and the humanities.

During the first semester the hermeneutic tradition, the major phenomenological thinkers, the philosophy of science, and the sociology of knowledge are brought together in order to explore the meaning and practice of science. Much of our time is spent decoding the sacrosanct-myths of scientific objectivity, of neutral research, of researcher "contamination," of positivist assumptions about validity and replication. In this process of deconstruction, new and critical ways of understanding our lived-world emerge in the dialogue that ensues between class participants. The second semester, a four month period devoted to taking these phenomenological and hermeneutic understandings into the world of everyday life, finds us engaged in critical self-reflexivity, exploring our own biographical histories as prelude to exploring the worlds of our informants. We open ourselves to the world of literature, to fiction, poetry, and prose and explore the find parameters that separate Charles Dickens' Oliver Twist from Robert Coles' Children of Crisis or Barbara Myerhoff's Number Our Days from Tillie Olson's Tell Me a 
Riddle. At that point, it is appropriate to move beyond literature into "the field": into prisons, homes for the aged, lifeworlds of grandmothers, of factory workers, of women administrators, of childcare institutions. This creates an intersubjective and cross-cultural mosaic of life histories and portraits into which we are drawn, engaged as readers and interpretive critics of the life texts that are before us.

One of the most significant activities during this course sequence is the time we spend analyzing our own self-descriptions of remembered experiences (cf. Beekman, 1981). Topics have ranged from experiences of fear, to falling asleep, to childhood memories. This year we spent several weeks analyzing our childhood recollections of a favorite play space. Each class member wrote a brief description (2-3 pages max.) which was reproduced and circulated among our 20 class members. Several excerpts follow, evoking the landscapes of childhood play:

I would lock my door and climb onto the queen size, 100 year old oak bed, which had been my mother's when she was a child. I know by heart the design of the four smoothly carved posts with the large round knobs on top and the wood felt soft and cool to the touch. In moments of despair I would huddle at the bottom of the bed hugging one of the posts for comfort.

My favorite game was a personal version of Noah's Ark, and all my animals, dolls and paper dolls would reside safely on the Ark with me, where we would have adventures, read stories or take naps. Occasionally I would venture a foot off the bed onto the oval braided rug which looked like an island, but stepping onto the hard floor was disaster - that was the ocean or quicksand, depending on the game. (Beth)

or

I remember the large mulberry tree in the "far-back"-it was a secret place where only kids dared to venture. We used to climb up the huge tree, eat the juicy red mulberries and from our hiding place among the dark overhanging leaves, could "spy" into other back yards. Roy and I had an agreement that the top perch was a "shared space"-because the mulberry leaves were partly in his yard and partly in mine. We made a chute out to the leaves and would slide down, branches and twigs cracking and snapping and ripe mulberries squelching under us. Sometimes we took blankets and cushions and lined the hiding place to make it more cosy while we read comic books and ate bubblegum. I was the only girl in the tree "gang"-all the other kids who we allowed up there were boys-but Roy and I were "Tree-Captains"-we were in charge!! When the wind used to blow over the ocean, the leaves would rustle, the branches would sway and I remember lying back imagining I were a ship's captain as the salty sea-spray blew over my face. Often we lay there for hours, hidden from adult eyes, giggling as our parents calledlooking for us in the distance. We, unseen, but seeing them far below. (Val) 
When there was hay in the barn, which filled my bleachers, the stacks were so high that I could not see the top. They had lots of bales, those stacks, and they changed from a fresh green color and smell in the summer to a musty dark color and smell in the winter. As the bales left so did the warmth and snow drifted in the barn to replace them.

The high ceiling was peaked so that I could usually not see the top clearly during daylight. Up there the barn birds, pigeons and swallows sat and talked. They played lots of games with me. We especially liked "Hot and Cold" where they helped me search for a lost peanut butter pail of marbles my brother said he hid in the barn beams. We looked for those marbles for years.

The best part of the barn for me was that I could sneak up there through the barnyard from the garden. I went from the barnyard into the basement and climbed through a hole in the floor. Nobody knew where I was. When they screamed for me, I would climb back through the hole and go out the basement. By coming in from the garden, I protected my personal place. (Mary)

The experience of collectively analyzing poignant moments from our own life histories created a sense of solidarity, intimate dialogue and respect among group members. Not only do traditional bounda. ries between instructor and student fade, but the rapport created by this mode of phenomenological analysis leads to creative insights We collectively identified several tentative themes:

- child as active transformer of her world

- sense of privacy as vital to the child

- sense of autonomy and control

- the dialectic of fearfulness and actively seeking danger

- acute sensory-body awareness

- memory of vivid concrete detail

- being the "seer" yet being hidden

- dialectic of private and public horizons.

We also realized how time-dependent our memories of play space were, and we began to question what makes a space "my place." Is ar adult reconstruction of a childhood experience qualitatively differ ent from a young child's actual experience? This question led $u$ each to interview a child - and this soon mushroomed into an inter generational set of interviews-our youngest informant was three and oldest 84 years! Several cross-cultural protocols were gatherec -from Korea, India, Mexico.

When we reconvened as a group, we xeroxed all our interviews, col lectively analyzed three individual cases in class and then eacl member wrote a second analysis of the play space experience, nor enriched by the "thick descriptions" of our informants. Once agail we found that there was a startlingly powerful memory of sensor: images-held intact over 80 years in some instances. In addition, th imbuing of space with action and personal agency, the personalizin of private space, the dialectic between security and adventure, al re-emerged as vivid experiential themes. Spaces varied fron 
kitchens, to barns, to trees, to holes, to chairs; yet the action narrative and the setting of personal and social horizons was part of the landscape of childhood play. We all carried our special places within us-time-bound, often time-fixed in a certain chronological age-sequence. But the extent to which our images of the playspace dominated and, in some cases, consumed our present realities was striking. Once again, to look "with fresh eyes" at the commonplace led to a creative and exciting group experience. As both informants and interpreters, we began to recreate T. S. Eliot's Little Gidding:

The end of all our exploring

Will be to arrive where we started

And know the place for the first time

Through the unknown remembered gate

When the last of earth left to discover

Is that which was the beginning. (Eliot, 1963, p. 272)

After we create living texts out of our own experiences, we are then in a position to begin to document the lifeworlds of others, to listen to the many voices that emerge when research becomes an embedded activity, grounded in the rituals of our informants' daily reality, mediated by specific contexts and culture.

Research as praxis then emerges as both a personal and social commitment. As Jean Paul Sartre said, "To understand is to change, to go beyond oneself" (Sartre, 1968, p. 18). Research as an act of commitment involves the fine-comb exploration of densely textured moments-micro-events that illuminate and stretch beyond the immediacy of the context in which they occur. In Clifford Geertz's words, "small facts speak to large issues," and the phenomenological descriptions and thematizations that we construct of several unique lives speak with vivid actuality to lives beyond our own. To call on intersubjectivity then becomes not an issue of positivist validation but, rather, one of poetic resonance, of the evocation of other scripts and other images in other lives.

But ultimately our work and project belongs to the age-old art of storytelling. It is no mistake that one of Walter Benjamin's most perceptive essays in Illuminations is devoted to "the storyteller." Benjamin tells us, in much the same way that Merleau-Ponty does, that our pre-understanding, our primary modes of experience, must be returned to-for indeed the more deeply "the story" is integrated into the experience of the listener, the greater is the latter's inclination to continue to tell and so to continue the life of the story within a community of listeners. "For storytelling is always the art of repeating stories, and this art is lost when the stories are no longer retained. It is lost because there is no more weaving and spinning to go on while they are being listened to" (Benjamin, 1968, p. 91).

It is the weaving and spinning-the interlacing of the threads of our lives and the lives of others that constitute our phenomenological texts. It is here that our praxis finds its origins and creates the possibilities for a human literacy. 


\section{References}

Beekman, T., \& Mulderij, K. (1981). Beleving en Ervaring.( 2nd ed.) Meppel: Boon.

Benjamin, W. (1969). Illuminations. New York: Schocken Books.

Eliot, T. S. (1963). Collected poems 1909-1962. London: Faber and Faber.

Freire, P. (1970). Pedagogy of the oppressed. New York: Seabury Press.

Freire, P. (1973). Education for critical consciousness. New York: Seabury Press.

Geertz, C. (1973). The interpretation of cultures. New York: Basic Books.

Greene, M. (1978). Pedagogy and Praxis. In Landscapes of Learning. New York: Teacher's College Press.

Greene, M. (1980, Summer). Breaking through the ordinary: The arts and future possibility. Journal of Education, 162(3), 18-26.

Murray, M. (1975). Modern critical theory: A phenomenological introduction. The Hague: Martinus Nijhoff.

Sartre, J. P. (1968). Search for a method. New York: Vintage Books. 